\title{
DEDICATION: FRANK MORTON CARPENTER
}

\author{
EDWARD O. WILSON
}

In his 91 st year, Frank Carpenter may look back (his admirers trust with satisfaction) on a career of length and richness almost unprecedented in the history of American Entomology. Born in Boston, Massachusetts, on September 6, 1902, he became a granitic, seemingly almost permanent presence in Harvard biology through most of the present century. He began attending meetings of the Cambridge Entomological Club at the age of 16, he became a member during his freshman year at Harvard in 1922, and he has remained a particularly active participant and guiding light of that organization for 75 years-for well over more than half its history.

Carpenter graduated magna cum laude from Harvard College in 1926, took a master's degree the year following, and his Sc.D. under the direction of William Morton Wheeler in 1929. He joined the Harvard faculty in 1932 and advanced to occupy two prestigious chairs in succession, one of several Alexander Agassiz Professorships of Zoology and, later, the Fisher Professorship of Natural History. He retired in 1973, but has remained fully engaged at the Museum of Comparative Zoology as Honorary Curator of Fossil Insects since that time.

Steadfastness, integrity, and selfless devotion to a chosen discipline, marked by a steady advance in scientific knowledge, have defined his career. For generations of students at Harvard, he was entomology embodied, in the elementary and advanced courses of instruction he taught, as well as in the counsel he gave to students and colleagues at every level. Among his other formal activities he trained no fewer than 31 doctoral students in entomology, invertebrate zoology, and paleontology.

For over forty years Professor Carpenter (it was hard for even his older alumni to call him Frank, although he encouraged that) served as editor and driving spirit of Psyche and Treasurer of the Club. He invested his skills and Yankee thrift to keep the subscription price at what surely was the lowest of any internationally prominent journal published in this country. He led Psyche to foremost rank among the best entomological publications in the world, with articles of consistently high quality in paleontology, social 


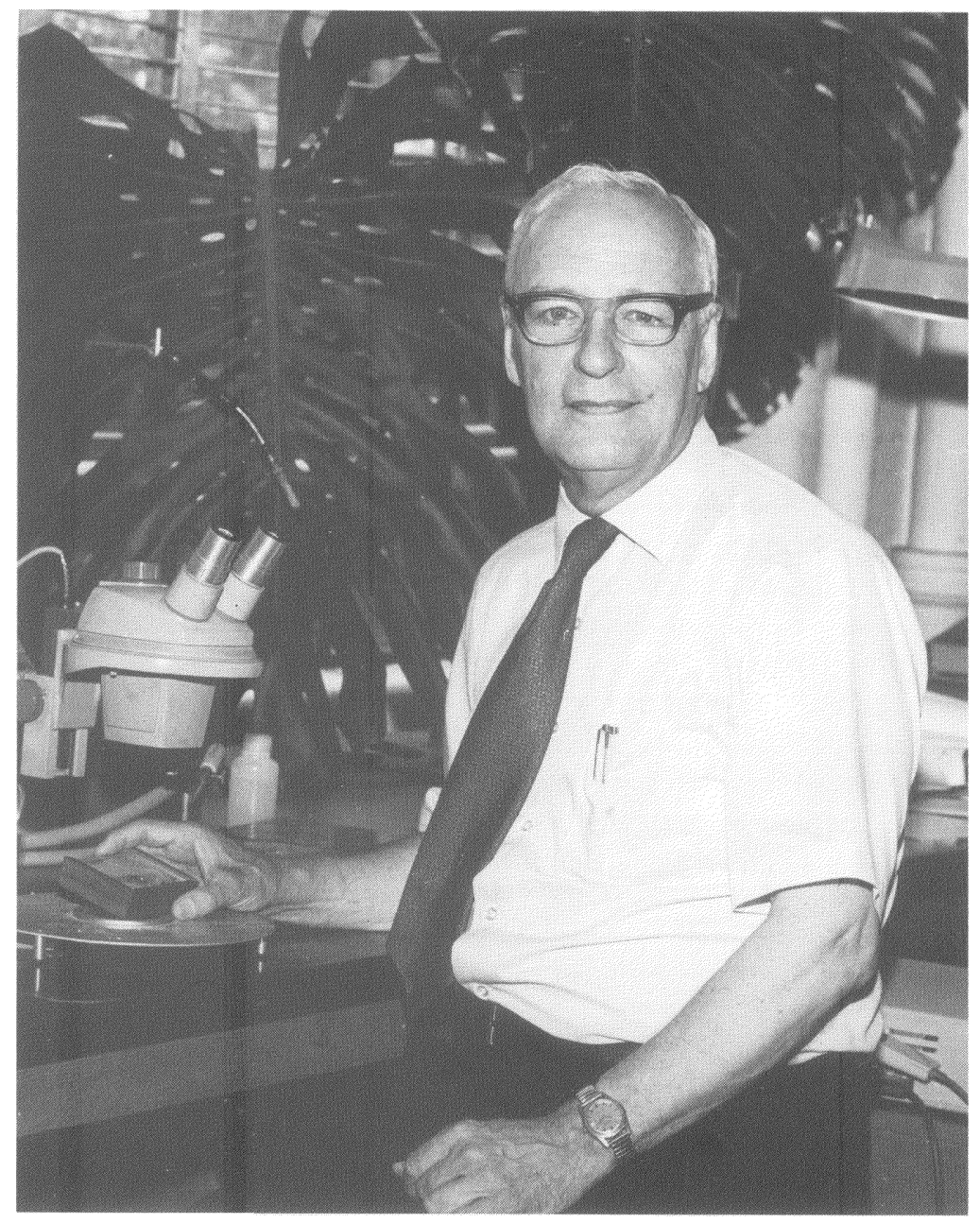

Frank Morton Carpenter 
insects, anatomy, systematics, and behavior, and other topics. His administrative duties at Harvard remained numerous throughout this time. His outside activities included service as Vice-President of the American Academy of Arts and Sciences and National President of the Scientific Research Society (Sigma Xi).

Frank Carpenter is the world authority on fossil insects and insect macroevolution, by virtue of his lifelong contributions and encompassing expertise. His two-volume masterwork, the Hexapoda portion of the Invertebrate Paleontology Series of the Geological Society of America, was published in 1992. At the age of 90, Carpenter thus completed his long-awaited synthesis. And it is about everything in the fossil history of insects, exhaustively researched down to virtually every reference in every language across the entire history of the subject. It is not likely to be repeated for decades - at least not by any one author. Much of the work reported came from the microscope and pen of Carpenter himself, and many of the specimens described are from the collection of the Museum of Comparative Zoology, which, thanks to Carpenter, is today one of the two largest and most comprehensive in the world (the other is in the Paleontological Institute of the Russian Academy of Natural Sciences, Moscow).

Carpenter brought two major strengths to the study of the insect fossil record. The first was his expertise in the modern fauna and the concepts and techniques of general biology needed to study it. Much of his research was on living representatives of the primitive orders Neuroptera and Mecoptera. He is one of three co-authors of The Classification of Insects, the monumental treatise that covers the entire living world fauna. The second reason for his success was his concentration on the Paleozoic Era. Unlike vertebrates, insects have changed relatively little since the beginning of the Tertiary Period. Many families and even genera have persisted since Eocene and Oligocene times. Looking farther back in time to the Mesozoic, we find many more replacements at the level of the family and the order; but it is in the Paleozoic that virtually a whole new world is encountered. Carboniferous and Permian insects were evidently as dominant and as diverse-at least at the ordinal level-as they are today, but the orders were mostly different. It was into this world that Professor Carpenter projected his intellect, personally collecting many of the fossils, and over a 
period of many years, conducting the herculean task of classification at the level of the order and family. He illuminated the first great wave of insect evolution.

For his scientific contributions Frank Carpenter received the 1975 Paleontological Society Medal, the highest honor given in the discipline. For his innumerable but perhaps less obvious achievements in education, editing, and mentoring, and for the wide impact he has had in entomology, he receives the gratitude of the small army of his admirers and followers. We warmly dedicate this final issue of the 1992 Psyche to Frank Carpenter 90 years after his beginning.

Edward O. Wilson

March 7, 1993 

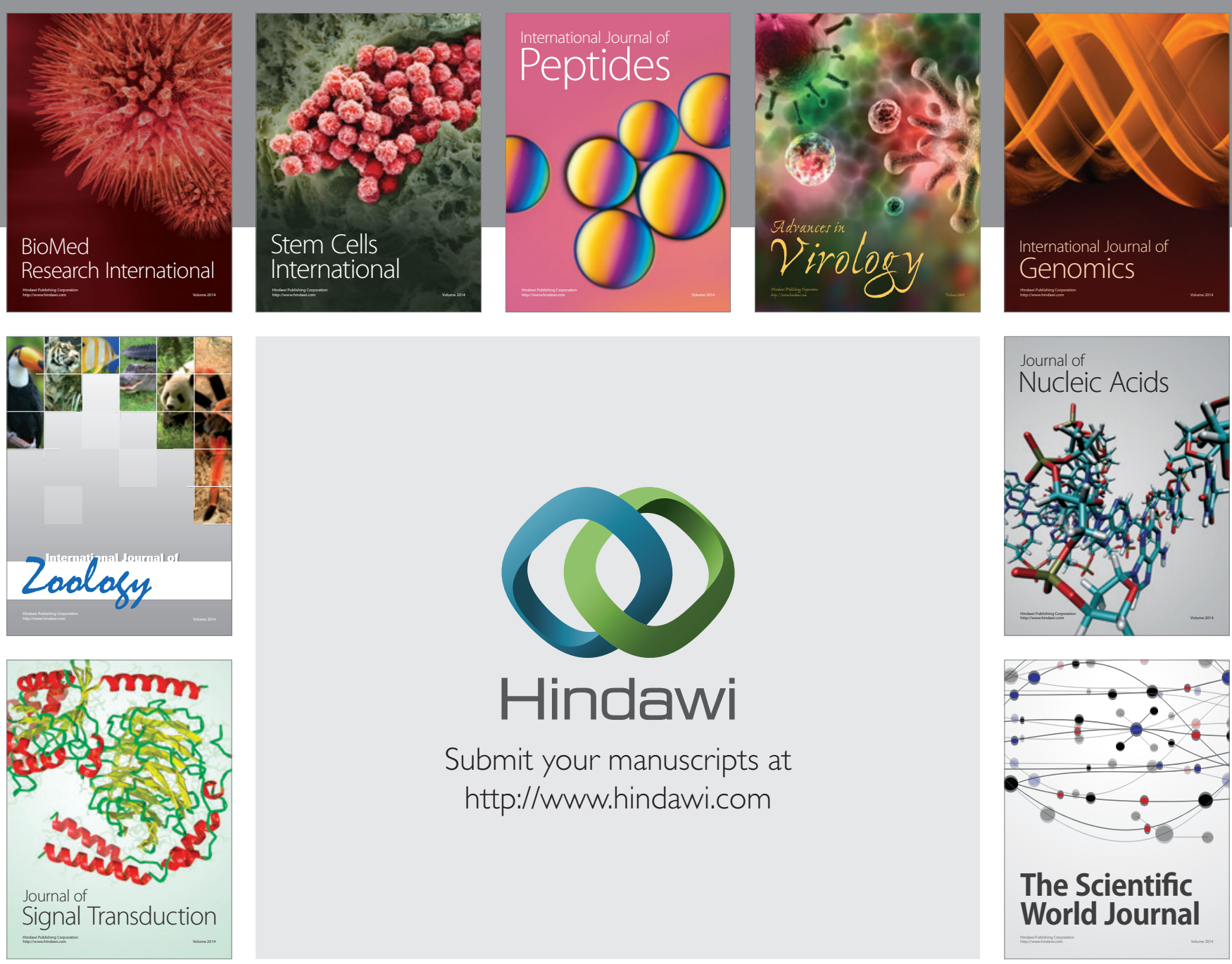

Submit your manuscripts at

http://www.hindawi.com
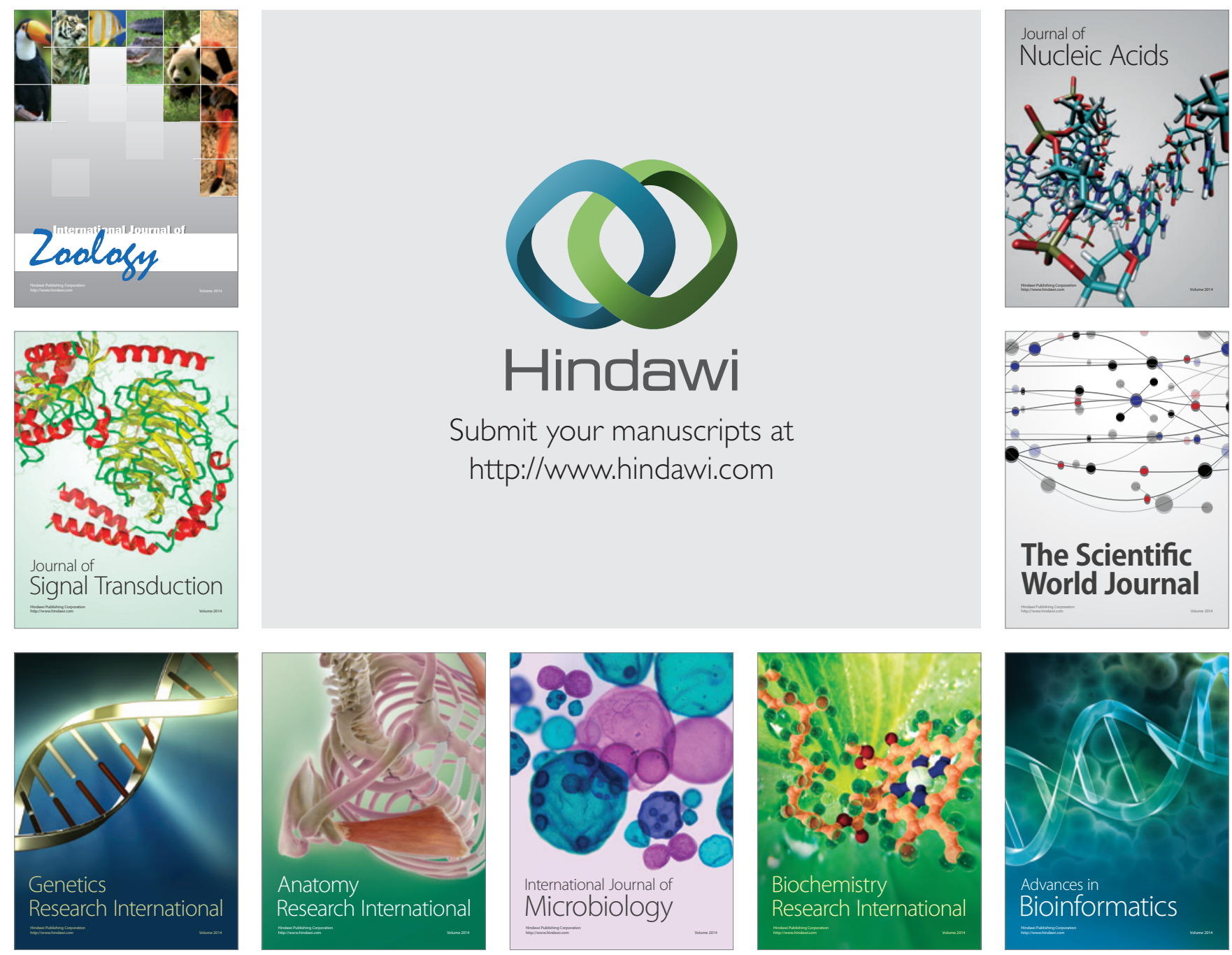

The Scientific World Journal
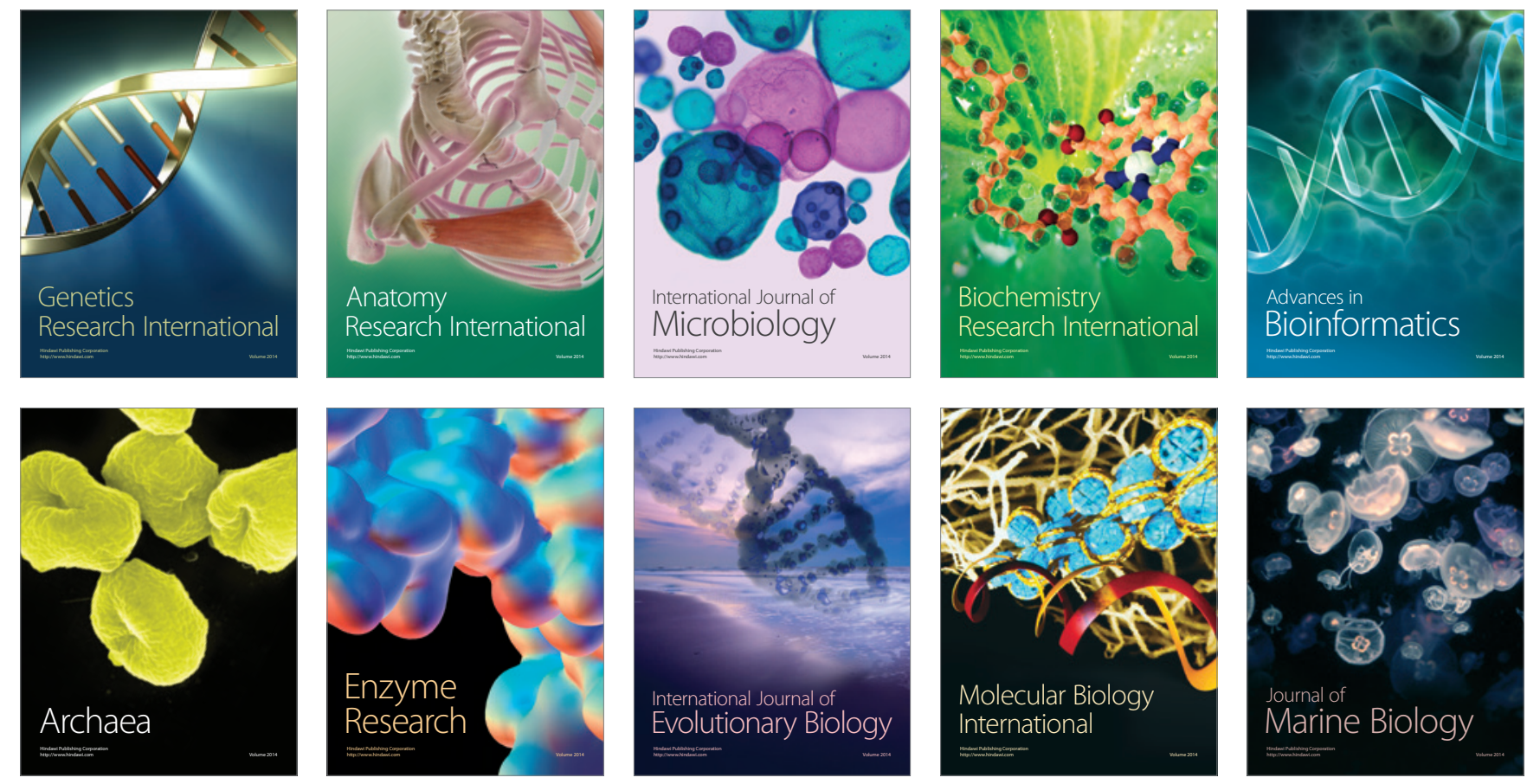